\title{
Treatment of chronic constipation with lactulose syrup: results of a double-blind study
}

\author{
A. WESSELIUS-DE CASPARIS, S. BRAADBAART, G. E. v.d. BERGH-BOHLKEN, \\ AND M. MIMICA
}

\author{
From the Clinical Research Department, N.V. Philips-Duphar, Netherlands, Geriatric Centre, Rotterdam, \\ State Psychiatric Home, Eindhoven, and the Dr. J. Kajfes Hospital, Zagreb
}

Although correction of faulty bowel habits and a change in dietary regimen is helpful in many cases of constipation, there remains a group of patients who cannot easily accept the prescribed regimen, or in whom no desired effect is obtained. It is here that there is a need for effective bowel regulation without the use of drastic laxatives. Because prolonged treatment of what is essentially a harmless disease may be required, a bowel regulator must be carefully chosen. It should have a gentle effect, without any systemic action (presumably therefore not absorbed), no adverse effects such as cramps or salt depletion, and no contraindications, and it must be neither toxic nor habit forming.

Since lactulose ${ }^{1}$, first studied by Mayerhofer and Petuely (1959), largely meets these requirements, we have carried out a double-blind study of the effect of lactulose in patients with severe constipation.

Lactulose, $\beta$-galactosido-fructose, is a synthetic disaccharide which is not digested in the small intestine since the specific disaccharidase is lacking (Dahlqvist and Gryboski, 1965). It passes unchanged into the colon where it serves as an energy source for the carbohydrate-splitting bacteria, predominantly Lactobacillus acidophilus and $L$. bifidus. During this fermentation process low molecular organic acids (mainly lactic and formic) are formed (Haenel, Feldhein, Müller-Beuthow, and Ruttloff, 1958; Hoffman, Mossel, Korus, and van der Kamer, 1964), which in turn lower the $p H$ of the stool (Bircher, Müller, Guggenheim, and Haemmerli, 1966).

One hundred and three elderly patients of either sex (26 in Rotterdam, 38 in Eindhoven, and 39 in Zagreb), who were regularly taking laxatives for the treatment of chronic constipation, were studied.

\section{EXPERIMENTAL ARRANGEMENT}

The patients were allocated at random to two groups, to

${ }^{1}$ Lactulose syrup $50 \%$, trade-name Duphalac, N.V.Philips-Duphar, Amsterdam, Netherlands. be treated for three weeks with either lactulose syrup 50\% or with placebo (glucose syrup). The lactulose syrup and the glucose syrup, which were of identical appearance and taste, were supplied in coded bottles, numbered at random, so that neither the patients nor the nurse knew which one was being administered.

After a pre-treatment period of two weeks, during which the frequency of defaecation and the quantity and brand of laxatives were recorded daily, treatment with syrup was started after the first defaecation in the third week. The initial dose of $15 \mathrm{ml}$ daily was administered every day at $4 \mathrm{p} . \mathrm{m}$. The daily dose was reduced by half ( $8 \mathrm{ml}$ daily) after three consecutive days with defaecation, but if no defaecation occurred for more than $\mathbf{4 8}$ hours, the dose was doubled (i.e. from 15 to $30 \mathrm{ml}$ or from 8 to $15 \mathrm{ml}$ daily). If no defaecation occurred on three consecutive days with the doubled dose, a laxative was administered according to the previous therapeutic regimen. If defaecation occurred on three consecutive days with the doubled dose, the patient was treated again with the former dose but if the response on the doubled dose remained unsatisfactory, treatment with $30 \mathrm{ml}$ syrup daily was continued until three weeks were completed. After three weeks' treatment the frequency of defaecation was recorded for another two weeks, during which no treatment took place.

This post-treatment period was included in the experimental scheme in the first place to assess a possible carry-over effect of lactulose, which would show itself in a reduction of the number of those using laxatives in the post-treatment period. Laxatives, however, were prescribed only if defaecation did not occur for more than 48 hours.

\section{RECORDING OF DATA}

Records were made of the frequency of defaecation, the daily dose of syrup, and possible side-effects.

\section{CRITERIA FOR EFFECTIVENESS}

The criterion by which the effectiveness of the treatment of lactulose was estimated was the need for additional laxatives during the treatment period. The treatment was 
considered to be a success if the patient needed no laxatives at all or only once in $\mathbf{2 1}$ days.

\section{RESULTS}

Since the figures were obtained in three different centres, we first compared the results in each centre but in view of the small differences between them, it seemed justifiable to take the results together.

The results quoted in Table $I$ indicate that the success rate in the lactulose group $(86 \%)$ was higher than in the placebo group $(60 \%)$, the difference being statistically significant $(P<0.02)$.

The high success rate in the placebo group was surprising and led us to further evaluation.

TABLE I

USE OF LAXATIVES IN TREATMENT PERIOD

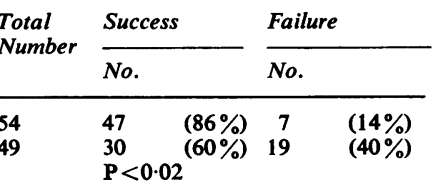

TABLE II

USE OF LAXATIVES DURING POST-TREATMENT PERIOD

\begin{tabular}{llllll} 
& \multicolumn{2}{l}{ Need for Laxatives } & & \multicolumn{2}{l}{ No Need for Laxatives } \\
\cline { 2 - 3 } & No. & & & No. & \\
\hline Lactulose & 31 & $(57 \%)$ & 23 & $(43 \%)$ \\
Slucose & 21 & $(43 \%)$ & 28 & $(57 \%)$ \\
Significance probability & & $P=0.20$ &
\end{tabular}

From the results given in Table II it appears that the percentage of lactulose-treated patients who did not need laxatives in the post-treatment period is not statistically different from the percentage in the placebo group. It can therefore be concluded that lactulose did not show a carry-over effect.

We subdivided the 103 patients into two groups: 51 patients who did not need laxatives during the post-treatment period, and 52 patients who needed laxatives during that period. Only this latter group can be considered as genuinely suffering from constipation, and their responses to lactulose and glucose are given in Table III.

\section{TABLE III}

USE OF LAXATIVES IN TREATMENT PERIOD BY PATIENTS NEEDING LAXATIVES IN THE POST-TREATMENT PERIOD (TRULY CONSTIPATED)

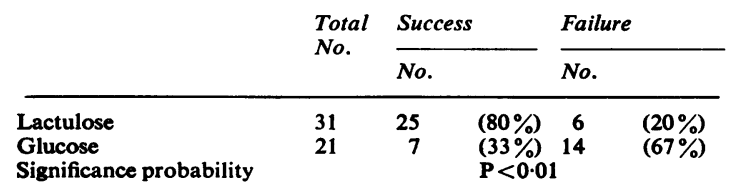

Table III gives a proper picture of the success rate of the treatments in this trial and shows that in this group of patients lactulose was significantly better than glucose in promoting defaecation in constipated subjects.

\section{DISCUSSION}

There is little agreement as to what constitutes normal bowel habit. In a study of two populations the number of actions per day was used as the criterion (Connell, Hilton, Irvine, Lennard-Jones, and Misiewicz, 1965) and in this study it was concluded that the normal range extended from three actions per day to three per week. However, other factors, such as the hardness of the stool or the degree of straining necessary for defaecation, have not been considered, and it is difficult to obtain objective criteria for these features.

In this study we accepted the dependence of the patient on laxatives for regular bowel activity as the most objective criterion. However, in the course of the trial it became apparent that about $50 \%$ of patients did not need laxatives in the post-treatment period, although all used laxatives in the pretreatment period and considered themselves to be chronically constipated. Thus the patients in this study form a less homogeneous group than was supposed. The inclusion of some patients who were not truly constipated masks the effects of the treatments but in those who were truly constipated a marked superiority of lactulose over glucose emerged.

Lactulose forms a new principle in the treatment of constipation, probably because it exerts its effect by alteration of the intestinal flora. Theoretically all sugars have this property, provided that they reach the colon unchanged, but in healthy individuals the intestinal disaccharidases split them into readily absorbed monosaccharides. However, in disaccharidase deficiency or in disaccharidase overloading, the sugar reaches the colon unchanged and leads to increased fermentation, producing low molecular weight organic acids which in turn may affect colonic motility.

This trial also proves that assessment of the need for laxatives is very difficult and that laxatives are often taken unnecessarily. Therefore it is most important to have a harmless drug for bowel regulation. Lactulose is a completely harmless substance: in recommended doses an easy defaecation is obtained without cramps. It does not affect blood sugar levels in diabetic patients (Wiebenga, personal communication) and in our experience it is not habit forming. The only side effect sometimes observed is transient gas formation and intestinal bloating. 


\section{SUMMARY}

The effect of lactulose has been studied in a doubleblind trial conducted in three different centres.

One hundred and three regular laxative users were included in these trials. It appeared that approximately half of them (51) did not need a laxative at all, because they had a regular defaecation in the post-treatment period in which all laxatives were withheld. In these 51 patients there was no significant difference between the effect of lactulose and glucose. In 52 truly constipated patients the effect of lactulose could be measured. The success rate for lactulose was $80 \%$, for the placebo $33 \%$. The difference in success rate is highly significant $(\mathrm{P}<0.01)$.

We would record our gratitude to Mr. R. van Strik,
Research Laboratory, for the statistical evaluation of the results.

\section{REEERENCES}

Bircher, J., Müller, J., Guggenheim, P., and Haemmerli, U. P. (1966) Treatment of chronic portal-systemic encephalopathy with lactulose. Lancet, 1, 890-893.

Connell, A. N. Hilton, C., Irvine, G., Lennard-Jones, J. E., and Misiewicz, J. J. (1965). Variations of bowel habit in two population samples. Brit. med. J., 2, 1095-1099.

Dahlqvist, A., and Gryboski, J. D. (1965). Inability of the human small-intestinal lactase to hydrolyze lactulose. Biochim. biophys. Acta (Amst.), 110, 635-636.

Haenel, H., Feldhein, W., Müller-Beuthow, W., and Ruttloff, $\mathbf{H}$ (1958). Versuche zur Umstimmung der faecalen Flora des gesunden Erwachsenen, Eugalan-Töpfer, Lactose, LactuloseSirup nach Petuely. Zbl. Bakt. I. Abt., 173, 76-96.

Hoffmann, K., Mossel, D. A. A., Korus, W., and Kamer, J. H. van de (1964). Untersuchungen über die Wirkungsweise der Lactulose ( $\beta$ - Galactosido-Fructose) im Darm. Klin. Wschr., 42, 126-130.

Mayerhofer, F., and Petuely, F. (1959). Untersuchungen zur Regulation der Darmtätigkeit des Erwachsenen mit Hiefe der Laktulose (Bifidus-Factor). Wien. klin. Wschr., 71, 865-869.

Wiebenga, A. H. Personal communication. 